\title{
Index of Historical Persons
}

A

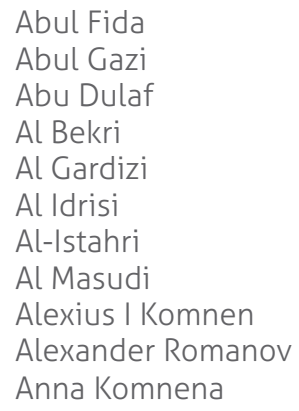

Abul Fida

Abul Gazi

Abu Dulaf

Al Bekri

Al Gardizi

Al Idrisi

Al-Istahri

Al Masudi

Alexius I Komnen

Alexander Romanov

Anna Komnena

B

Benedictus Polonus

Bilge-Khan

Burdhzogly, Burchevitsch

D

del Carpine, Giovanni da Pian 17, 40, 55

G

Gallus Anonymus von Graff, Viktor Gujuk $73,74,75,76,107$
17

I

Ibn Batutta

Ibn Chordadbek

Ibn Fadlan

Ibn Said

Innocent IV
27,29

48

28

27

27

27,50

27

27,28

27

73

27

17

43

51
27

27,29

17

\section{K}

Köl-Tegin

20,32

L

Lassota von Steblau, E. $\quad 18,42$

Lerche, ]. J.

Louis IX

18

17

$M$

Mahmud of Kashgar $\quad 27$

Matthiew of Edessa

N

Nicholas I Romanov $\quad 73$

Nizami

50,55

$\mathbf{R}$

Radziwitt 25, 28

Radziwitt, Helen 25

Rashid ad Din 27

Rohoziński, Ernest 25

de Ruysbroec, Willem 17, 20, 34, 47, 50, 55

S

Sharukan 51

von Strahlenberg, Ph. J. $\quad 18,42$

27 T

27 Tamim Ibn Bahr $\quad 27$

\section{V}

Vladislav IV the Exile 